\title{
Factors associated to risk of malnutrition amongst elderly women in low-income communities
}

\section{Factores asociados al riesgo de desnutrición en mujeres mayores en comunidades de bajos ingresos}

\author{
Jair Sindra Virtuoso-Júnior, Dr ${ }^{1}$, Sheilla Tribess, Dr ${ }^{1}$, \\ Vicente Romo-Perez, $\mathrm{PhD}^{2}$, Ricardo Oliveira-Guerra, $\mathrm{Dr}^{3}$
}

\section{Summary}

Objective: The present study aimed to identify the prevalence and the factors associated with the risk of malnutrition in elderly women.

Methods: The study deals with a cross-sectional design, with a sample of 222 women in the age group from 60 to 96 years of age. An interview was carried out containing socio-demographic variables, clinical conditions, and behavioral aspects. The statistical analysis was accomplished via calculation of the respective prevalence ratios (PR) in the Poisson regression, $\mathrm{p}<0.05$.

Results: A prevalence of $33.8 \%(\mathrm{n}=75)$ of women, considered with a malnutrition risk or undernourished, which started from the hierarchical multivariate analysis, was identified. A significant association with the age group ranging from 70 to 79 years of age $(\mathrm{PR}=2.1$; CI 95\%: 1.3-6.7), low education level $(\mathrm{PR}=3.1$; $\mathrm{CI} 95 \%$ : 1.0-11,6), living with other people ( $\mathrm{PR}=2.0$; CI 95\%: 1.0-4.6), the presence of depressive symptomatology ( $\mathrm{PR}=2.1$; CI 95\%: 1.0-7.1), absence of administration of medication ( $\mathrm{PR}=3.0$; $\mathrm{CI} 95 \%$ : 1.1-7.6), having had some food privation along their lives ( $\mathrm{PR}=3.1$; CI 95\%: 1.3-9.6), and with less than $75 \%$ of the time of physical activity in their leisure time ( $\mathrm{PR}=2.0$; CI 95\%: 1.0 4.7) were found.

Conclusion: There is a high percentage of elderly women in situation of malnutrition risk, and the associated factors to the condition suggests a complex causal net in the determination of the nutritional state.

Keywords: Nutritional status; Health status; Socioeconomic factors.

Colomb Med. 2012; 43: 54-62

\section{Resumen}

Objetivo: Identificar la prevalencia y los factores asociados con el riesgo de desnutrición en mujeres mayores.

Métodos: Diseño transversal, con una muestra de 222 mujeres con edades entre 60 y 96 años. Una entrevista que se llevó a cabo contiene las variables sociodemográficas, condiciones clínicas y aspectos conductuales. El análisis estadístico se realizó con el cálculo de razón de prevalencia (RP) correspondiente en la regresión Poisson, p $<0.05$.

Resultados: La prevalencia de 33.8\% ( $\mathrm{n}=75)$ de las mujeres, se considerada con un riesgo de malnutrición o desnutrición. A partir del análisis multivariado jerárquica, se identificó una asociación significativa con el grupo de edad entre 70 y 79 años ( $R P=2,1$; IC 95\%: 1.3-6.7), bajo nivel educativo ( $R P=3.1$; IC 95\%: 1.0-11.6), que viven con otras personas ( $\mathrm{RP}=2.0$; IC 95\%: 1.0-4.6), la presencia de sintomatología depresiva ( $\mathrm{RP}=2.1$; IC 95\%: 1.0-7.1), la ausencia de la administración de medicamentos ( $\mathrm{RP}=3.0$; IC 95\%: 1.1-7.6), después de haber tenido algunas privaciones de

Instituto de Ciências da Saúde, Universidade Federal do Triângulo Mineiro, Uberaba, Brazil. e-mail: jair@ef.uftm.edu.br sheilla@ef.uftm.edu.br

Facultad de Ciencias de la Educación y del Deporte, Universidad de Vigo, Pontevedra, España. e-mail: vicente@uvigo.es

Departamento de Fisioterapia, Universidade Federal do Rio Grande do Norte, Natal, Brazil. e-mail: roguerra@ufrnet.br

Received for publication March 3, 2011 Accepted for publication November 3, 2011 
alimentos a lo largo de su vida ( $\mathrm{RP}=3.1$; IC 95\%: 1.3-9.6) y con menos del $75 \%$ del tiempo de actividad física en su tiempo libre ( $\mathrm{RP}=2.0$; IC 95\%: 1.0-4.7).

Conclusión: Existe un alto porcentaje de mujeres mayores en situación de riesgo de desnutrición y los factores asociados con la condición sugieren una compleja red causal en la determinación del estado nutricional.

Palabras clave: Estado nutricional;

Condiciones de salud; Factores socioeconómicos.

Colomb Med. 2012; 43: 54-62

According to the American Association of Public Health, nutritional status can be defined as «the health condition of an individual influenced by the consumption and utilization of nutrients and identified by the relationship with the physical, biochemical, clinical and dietary factors» ${ }^{1}$. The nutritional state is an important indicator in the diagnosis of the population's health conditions. In older individuals, nutritional condition seems to be a synthesis of the habits and behaviors along their lives, concomitant with the genetic and environmental aspects.

It is critical to understand the bodily changes that occur during the normal aging process, especially in developing countries, where the elderly population presents early functional aging. In spite of the obesity epidemic that is seen in several countries around the world ${ }^{2-4}$, the nutritional quality cannot be ignored in the nutritional diagnoses of populations, given that an individual can be classified in an overweight condition and/or as being obese and at the same time be undernourished.

In general, in Brazil there is a tendency of the population to think that only individuals of low weight would be in a state of malnutrition state. This fact contributes to the ineffectiveness of the actions addressing behavioral changes related to the nutritional quality. Studies of prevalence of nutritional state in elderly individuals indicate a high number of people classified as overweight or obese ${ }^{3,4}$. However, the indicator commonly used in those studies is the Body Mass Index (BMI, which is the result of the ratio between body mass (kg) and height $(\mathrm{m})$ squared.
However, such indicator has been questioned in the assessment of elderly populations because the classification is similar for younger individuals ${ }^{5}$; additionally, malnutrition indexes are being underestimated and according to this criteria the indicator is linked with low weight classification. The body changes with aging; in that case, these changes are not being considered when the same criteria are used in the classification of the nutritional state of people in different age groups.

The assessment of nutritional status in elderly populations should consider, among other things, a complex web of factors, where social isolation, loneliness, chronic illness, disability, and physiological changes characteristic of aging processes can be reported ${ }^{1}$. Another aspect to be considered comes because of the existing investigations that mostly address the populations from great urban centers. In spite of the fact that the inhabitants of those places are not free from poverty, such cities in general offer more access to information compared to less populated cities.

There is, therefore, a need to identify the conditions related to the risk of malnutrition in the elderly in low-income and low-education populations. The purpose of the present investigation was to identify the prevalence and the factors associated with the risk of malnutrition in low-income elderly women. The results obtained are useful in the formulation of effective strategies to address the reduction of the malnutrition in the elderly in low-income communities.

\section{Materials and methods}

A cross-sectional study was accomplished in the municipal district of Jequié, located $365 \mathrm{~km}$ from Salvador, capital of Bahia, Northeast of Brazil, from October to December 2006. The city of Jequié has a Human Development Index (HDI) of 0.694 (an index below the country's HDI of 0.804) and a Gross Domestic Product (GDP) per capita of US \$ 5,260.

The HDI is a comparative measure of wealth, 
literacy, education, life expectancy, birth, or other factors for countries around the world. Although the GDP of the municipality is a reasonable measure, when analyzing the reality of the city it can be noted that most of the income is restricted to a few individuals, something common in many cities in Latin America.

A sample of 222 elderly women, 60 years of age or above was selected by using a probabilistic and stratified form by coexistence group. The value of the sample was proportional to $42.3 \%$ of the initial population of 528 elderly individuals that represents the total number of participant subjects in the 16 activity groups for the elderly people in the municipal district of Jequié, setting a 95\% confidence interval, $80 \%$ power test and error margin of $5 \%$.

Anthropometric measurements were accomplished for the assessment (weight, height, arm and calf circumference) and still, by individually applying a multidimensional questionnaire. Such an instrument was constituted by the following items:

- Socio-demographic aspects: age, education, marital status, labor activity, size of the family, and socio-economic level ${ }^{6}$. Regarding the economic issue, the Brazilian Economic Classification Criteria (BECC), developed by the Brazilian Association of Company Research (BACR), was used for the economic classification of the subjects. The BECC is a questionnaire used to divide the subjects into different economic classes. The criterion assigns value points according to each household characteristic and performs the sum of these points. The maximum score of the instrument is 34 , where the $\mathrm{A} 1, \mathrm{~A} 2, \mathrm{~B} 1$ and B2 classes (score of 17 to 34) represent the superior stratum, the $\mathrm{C}$ class (score of 11 to 16$)$ the intermediate stratum and the $\mathrm{D}, \mathrm{E}$ classes (score below 11) represent thelowest economic stratum.

- Aspects of physical health: Mini Nutritional Assessment $(\mathrm{MNA})^{7}$ instrument that combines reported aspects with anthropometric measures checked in the Body Mass Index (BMI);

- The instrument compared to others commonly used as nutritional assessment show acceptable levels of confidence ${ }^{8}$. The total agreement between the Malnutrition UniversalScreening Tool (MUST) and the MNA was $61.7 \%(\mathrm{k}=0.196, \mathrm{p}=0.007)$, sensitivity of $18.8 \%$ and specificity of $100 \%$. The total agreement between the Mini Nutritional Assessment - Short Form (MNA-SF) and the MNA was $89.7 \%$ ( $K=0.792, \mathrm{p}<0.001)$, sensitivity of $84.4 \%$ and specificity of $94.4 \%$.

- Physical activity during their leisure time $\left(\mathrm{Pth}_{60}\right.$ Percentile $)^{9}$, arm and calf circumferences ${ }^{6}$ obtained; - self perception of health, pathologies according to the International Classification of Diseases $(\mathrm{ICD}-10)^{10}$, medications in continuous use, occurrences of falls, and number of hospital admissions within the previous six months.

- Functional capacity: instrumental activities of daily living (IADLs) for Lawton's index ${ }^{11}$. This index has a maximum score of 14 , which represents the maximum level of independence. The subjects who scored below 12, were assessed with a moderate or severe functional dependence.

- Aspects of mental health: in the assessment of the presence of depressive symptomatology, the Geriatric Depression Scale was used (GDS-15) ${ }^{12}$. The subjects who scored 5 or above were assessed with the presence of depressive symptomatology. - The Short Portable Mental Status Questionnaire $(\mathrm{SPMSQ})^{13}$ was used to assess the cognitive function. The subjects who scored between 4 and 7 were assessed with mild cognitive impairment. Individuals with severe cognitive impairment were excluded from the sample because they are unable to answer the interview.

The Epidata software version $3.1 \mathrm{~b}$ was used for entry of the database and the analyses were done with the SPSS (version 15) statistical package. In the descriptive analysis, the distribution of absolute frequencies, percentile distribution, average, and standard deviation (SD) were made.

In the analytical approach, the proportion of elderly at risk of malnutrition was analyzed according to each independent variable. Raw and adjusted 
prevalence ratios (PR) with 95\% confidence interval (95\% CI) were calculated with Poisson regression ${ }^{14}$. Adjusted analysis was performed according to a three-level, hierarchical model determined a priori: 1) Socio-demographic; 2) health; 3) health-related behaviors. In this model, the effect of each variable on the outcome is adjusted for other variables in the same level or above in the hierarchical model ${ }^{15}$. For a variable to be retained in the model, significance level was set at $\mathrm{p}<0.20$. Statistical significance was established at $5 \%$.

This research followed the ethical principles of the Helsinki Declaration and Resolution No 196/96 of the National Health Council. The sectors of study (activity centers) authorized the research and the elderly were duly informed of the purpose of the study and informed about the voluntary participation. The research protocols were appraised and approved by the Research Ethics and Human Committee of the State University of Southwest Bahia (Opinion $\mathrm{N}^{\circ}$ 155/06).

\section{Results}

The study was conducted on a sample of 222 elderly women with an average age of $70 \pm 7.2$ years, the age variations ranged from 60 to 92 years. Table 1 shows a summary of the characteristics of the participants of this study. Although some variations have been observed in the age groups established, the population in general can be described with a predominance of widows, family arrangement characterized as being multi-generational, being of low education level and with most of the participants presenting low socio-economic classification.

Smoking has been referred to as a habit of the past by $37.4 \%(n=83)$, but in the present only $6.3 \%$ $(n=14)$ remains with such behavior. As for the practice of physical activities, an inverse phenomenon was observed. In the past, only $18.5 \%(n=41)$ practiced physical activities during leisure moments, while in the present such habit has been reported to have grown by $50.9 \%(n=113)$.
Table 1

The participant characteristics $(n=222)$

\begin{tabular}{lrr}
\hline \multicolumn{1}{c}{ Characteristic } & $\mathbf{n}$ & $\%$ \\
\hline Age (years) & & \\
$60-69$ & 115 & 51.8 \\
$70-79$ & 85 & 38.3 \\
$>80$ & 22 & 9.9 \\
\hline Marital status & & \\
Single/divorced & 43 & 19.4 \\
Married or living with the partner & 73 & 32.9 \\
Widow & 106 & 47.7 \\
\hline Family arrangement & & \\
Multiple generations & 100 & 45 \\
Socio-economical level & & \\
Classes D and E & 160 & 72.1 \\
\hline Time of education & & \\
<2 years & 121 & 54.5 \\
Solemnity-referred diseases & & \\
Circulatory system & 167 & 75.2 \\
Osteomuscle system & 159 & 71.6 \\
Diseases of the eyes & 119 & 53.6 \\
Diseases of the ear & 93 & 41.9 \\
Metabolic & 50 & 22.5 \\
Genitourinary system & 22 & 9.9 \\
Digestive system & 16 & 7.2 \\
Breathing system & 15 & 6.8 \\
Nervous system & 10 & 4.5 \\
Neoplasia & 04 & 1.8 \\
Infectious and parasitic & 04 & 1.8 \\
Hematopoietic & 02 & 0.9 \\
\hline & & \\
\hline
\end{tabular}

Nutritional state as verified by BMI demonstrated that $64 \%(n=142)$ of the samples could be classified in the overweight or obese (BMI over $24.9 \mathrm{~kg} / \mathrm{m}^{2}$ ) group. In the mini nutritional assessment, it was diagnosed that $35.6 \%(n=75)$ were classified as undernourished or with risk of malnutrition. Depressive symptoms were assessed for $18.9 \%$ 
$(n=42)$, and alteration of the cognitive state was identified in $75.2 \%(n=167)$ of the participants. The use of medications was referred by $72.2 \%(n=167)$, and $23.9 \%(n=53)$ stated that they took three or more medications per day. Self-reported diseases were within conformity of the International Classification of Diseases (ICD-10) ${ }^{10}$, and those related to the circulatory system, bone-muscular system, eyes, ears, and metabolic diseases were more referred by the elderly women interviewed, respectively. Other health conditions were reported; there is an example of occurrence of falls in the last three months reported by $21.2 \%(n=47)$ and of hospital admission in the last six months $15.8 \%(n=35)$. It is necessary to emphasize the fact that $46.8 \%(n=104)$ indicated some type of dependence on the moderate and/or severe type in the accomplishment of the instrumental activities of daily living (IADLs). However, the health condition noticed indicated that $33.8 \%(n=75)$ had an optimistic perception of their health condition and only $18.5 \%(\mathrm{n}=41)$ reported their health in «bad» condition.

The variables related only to the indicator of malnutrition risk are shown in Table 2 . The age group from 70 to 79 years of age was found associated with the risk of a state of malnutrition. Likewise, the accompanied living condition referred by the interviewees in relation to those who reported that they lived alone.

But regarding education, the illiterate elderly women had a higher prevalence of being in a malnutrition condition compared to those with education. The economic condition was also an important factor for the risk of malnutrition. Women with lower economic condition presented more prevalence of the risk condition for malnutrition, when compared with women of higher economic level. Another factor that seemed associated to the malnutrition risk that is usually tied to the economic condition was the fact that these people had some food deprivation throughout their lives.

The time spent on physical activities during leisure was dichotomized. Women who were qualified below the percentil $65\left(\mathrm{P}_{65}\right)$ presented prevalence for a risk of malnutrition three times higher, when compared to the subjects qualifying above this percentile. Similarly, individuals classified with the presence of depressive symptomatology had higher prevalence of malnutrition risk. Those people not taking medications had more malnutrition risk when compared to those who regularly took medications.

The raw results shown in Table 2 were good to determine the order of the blocks (models) and variables to be inserted in the hierarchical multivariate analysis to better explain the interactions among the characteristics reported by the elderly women in the study.

In Table 2, among the socio-demographic characteristics analyzed in an interacted form in the first block, just the age group from 70 to 79 years old, low education level and the fact of living accompanied, remained related to the malnutrition risk. In the second block analyzed, regarding the characteristics of health and controlled by the previous block, the presence of depressive symptomatology and the absence of medication usage remained in the hierarchical model. While in the third block, regarding behavioral characteristics, even when controlled for the previous blocks. It was verified that individuals qualifying below the $\mathrm{P}_{65}$ for physical activity presented prevalence two times higher for the condition of malnutrition, compared to those subjects more physically active during their leisure time. Also, those reporting some alimentary deprivation along their lives had more than three times prevalence of malnutrition risk compared to those that did not mention having had food deprivation.

\section{Discussion}

The condition of malnutrition represents a serious problem for the elderly person's health, taking into consideration the functional decline observed during that stage of life. People with bad nutritional quality tend to suffer more of chronic degenerative processes ${ }^{16,17}$. Understanding aspects associated to 
Table 2

Raw and adjusted prevalence ratios (PR), with 95\% confidence interval ( $\mathrm{Cl} 95 \%$ ), according to independent variables for older individuals from Jequié, State of Bahia, Brazil

\begin{tabular}{|c|c|c|c|c|}
\hline \multirow{3}{*}{ Characteristic } & \multicolumn{4}{|c|}{ Malnutrition risk } \\
\hline & \multicolumn{2}{|c|}{ Raw analysis } & \multicolumn{2}{|c|}{ Adjusted analysis } \\
\hline & PR [CI 95\%] & $\mathbf{p}$ & PR [CI 95\%] & $p$ \\
\hline \multicolumn{5}{|l|}{ Socio-demographic block } \\
\hline \multicolumn{5}{|l|}{ Age group (years) } \\
\hline $60-69$ & 1 & & 1 & \\
\hline $70-79$ & $1.96[1.08-2.87]$ & 0.01 & $2.12[1.33-6.72]$ & 0.02 \\
\hline$>80$ & $1.46[0.82-7.23]$ & 0.24 & $2.35[0.94-8.32]$ & 0.07 \\
\hline \multicolumn{5}{|l|}{ Economical level } \\
\hline Classes $A_{1}, A_{2}, B_{1}, B_{2}$ and $C$ & 1 & & 1 & \\
\hline $\mathrm{D}$ & $1.64[0.47-12.1]$ & 0.51 & $1.02[0.86-1.07]$ & 0.25 \\
\hline$E$ & $4.24[1.23-9.61]$ & 0.01 & $1.32[0.92-1.14]$ & 0.19 \\
\hline \multicolumn{5}{|l|}{ Education } \\
\hline Post elementary & 1 & & 1 & \\
\hline Illiterate & $3.14[1.12-8.72]$ & 0.04 & $2.98[0.96-9.35]$ & 0.07 \\
\hline Incomplete or complete elementary & $2.62[0.50-9.09]$ & 0.19 & $3.11[1.09-11.6]$ & 0.04 \\
\hline Living alone situation & 1 & & 1 & \\
\hline Accompanied & $2.42[1.16-4.89]$ & 0.01 & $2.04[1.09-4.67]$ & 0.02 \\
\hline \multicolumn{5}{|l|}{ Health block ${ }^{1}$} \\
\hline \multicolumn{5}{|l|}{ Depressive symptomatology } \\
\hline Absence & 1 & & 1 & \\
\hline Occurrence & $2.20[1.21-5.04]$ & 0.01 & $2.12[1.04-7.17]$ & 0.01 \\
\hline \multicolumn{5}{|l|}{ Medicines } \\
\hline Makes us & 1 & & 1 & \\
\hline Do not use & $3.40[1.12-5.47]$ & 0.01 & $3.03[1.19-7.63]$ & 0.01 \\
\hline \multicolumn{5}{|l|}{ Related behaviors the health block ${ }^{2}$} \\
\hline \multicolumn{5}{|l|}{ Physical activities (Leisure) } \\
\hline Above $\mathrm{P}_{65}$ & 1 & & 1 & \\
\hline Below $\mathrm{P}_{65}$ & $3.20[1.64-5.23]$ & 0.03 & $2.09[1.05-4.71]$ & 0.04 \\
\hline \multicolumn{5}{|l|}{ Privation of food along the life } \\
\hline Absence & 1 & & 1 & \\
\hline Occurrence & $3.68[1.32-9.24]$ & 0.01 & $3.1[1.31-9.62]$ & 0.01 \\
\hline
\end{tabular}

${ }^{1}$ Adjusted by the socio-demographic block.

2 Adjusted by the health and socio-demographic blocks 
risk of malnutrition contributes to more specific actions in health interventions directed at the elderly. In this discussion, we will approach the main aspects found in our results, considering as part of a decisive causal chain of conditions that contribute to the state of malnutrition.

In this study, the prevalence for a risk of malnutrition achieved superior score compared to other research assignments. The high percentage of individuals at risk of malnutrition can be partly understood, considering the differences used by the studies, in the construction of an indicator to assess the nutritional state. However, the individual components used as indicators of the risk for malnutrition have been outstanding in the literature as predictors of nutritional state in the elderly.

Increased age is associated to vulnerability for malnutrition. This fact seems to be an irreversible phenomenon, which is related to degenerative processes in the elderly. However, the social and cultural aspects can be the goals of public policies addressed to improve health conditions in impoverished communities ${ }^{19,21}$.

The results observed reinforce the findings of other studies ${ }^{19,21}$ that, in general, people classified in the lower strata of economic hierarchy, along with lower education levels are more exposed to negative habits related to the quality of ingested foods, partly due to lack of financial resources for the appropriate intake of necessary nutrients in the maintenance of the organic functions and for the lack of discernment when choosing the best foods on a daily basis.

The fact of living accompanied and being more exposed to conditions of malnutrition can be interpreted by taking into account the determinant of the functional capacity mentioned in an investigation of population base carried out in the municipal district of São Paulo, Brazil 22 . The authors of the study described that people who live alone tend to keep themselves more active in a function of the daily needs that cannot be transferred to somebody else. Nevertheless, it would be easier for those who prepare their favorite foods, in a way to minimize risk of malnutrition. However, in some elderly groups, the fact of living alone can worsen the condition of malnutrition. When these people are already in advanced phases of functional dependence, they do not get to prepare their own foods.

The health conditions reported by the elderly women who remained associated to the risk of malnutrition are different from the reported diseases. The presence of depressive symptomatology can be linked to several factors, among these include unsatisfactory conditions of life, home, family income, job.

In relation to medications, something interesting was observed; people who did not take medications had a higher prevalence of conditions of malnutrition risk compared to those who regularly took medications. This suggests that the non-use of medications is not related to the absence of health problems. This suggests that not using medications does not imply being healthy. Economic problems may affect the purchase of medications. The high prevalence of diseases reported by the elderly women was common, as reported in other population surveys ${ }^{3,23}$.

In the last block of variables, two characteristics stayed associated to the same risk of malnutrition when controlled by other investigated factors. The fact that it is below $75 \%$ in the time spent on leisure activities has shown it is associated to malnutrition risk and can be explained by the condition of physical inactivity. In general, the less active people physically tend to be the more dependent they are in their daily tasks ${ }^{21}$, which includes the condition of feeding or carrying out the preparation of their preferred meals.

The condition of having had some deprivation of foods throughout their lives makes us think about unfavorable economic status. In other words, people who did not eat in a satisfactory manner during some moment of their lives probably lacked financial resources. And even so, such people had more difficulties in the insertion and the attendance of a formal educational program.

Among the possible limitations of this study, we 
could point out the delineation of the research, where the fact of it being a cross-sectional study keeps us from being assured of implicit relationships of causality among the variables studied. However, through the information found in the literature, it allows us to infer that our results seem to support the evidence of the explanatory models of malnutrition risk in the elderly population.

The possibility of bias in the selection of the study is minimized, given that it used a sample selected from a homogeneous population when related to the socio-economic parameters found in the Brazilian northeast. In other words, social indicators show low stratum of economically devoided classes. The appraisers' prior training for application of the interview and anthropometrical measures largely eliminates the possibility of diagonal shift. It is worth noting the possibility that the results of the selfreported measurements may have some influence of cultural and social factors, such as the case of the low schooling shown in the sample.

The data analyzed data in this study allows concluding that more than a third of the interviewees and elderly individuals appraised revealed risk of malnutrition, and the age group from 70 to 79 years, low education level, the fact of living accompanied, presence of depressive symptomatology, absence of medication intake, short time spent in leisure physical activities and having had alimentary deprivations throughout their lives are decisive factors for risk of malnutrition in elderly women from the low-income group.

Therefore, physical inactivity (leisure) and the lack of foods along life could act as predictor factors of the risk of women's malnutrition, even when controlled by socio-demographic factors and related to health in the present. However, it is worth highlighting that physical activity, as well as food consumption is related to economic and cultural aspects throughout ones life. Therefore, the actions addressed to improve the nutritional quality of the elderly should be enforced by politicians who prioritize antipoverty programs, with betterincome distribution and access to education and leisure activities for the poor.

Conflict of interest. None of the authors has conflicts of interest related to this study.

\section{References}

1. Najas MS, Nebuloni CC. Avaliação nutricional. En:Ramos LR, Toniolo Neto J (eds). Geriatria e geontologia. Barueri: Manole; 2005; p. 299-314.

2. Da Cruz IBM, Almeida MSC, Schwanke CHA, Moriguchi EH. Prevalência de obesidade em idosos longevos e sua associação com fatores de risco e morbidades cardiovasculares. Rev Assoc Med Bras. 2004; 50: 172-7.

3. Rui-Arregui L, Castillo-Martínez L, Orea-Tejeda A, MejíaArango S, Miguel-Jaimes A. Prevalence of self-reported overweight-obesity and its association with socioeconomic and health factors among older Mexican adults. Salud Publica Mex. 2007; 49: 482-7.

4. Chang VW, Alley DE. The changing relationship of obesity and disability, 1988-2004. JAMA. 2007; 298: 2066-7.

5. Cervi A, Franceschini SCC, Priore SE. Análise crítica do uso do índice de massa corporal. Rev Nutr. 2005; 18: 76575.

6. ABEP. Associação Brasileira de Empresas de Pesquisa. Critério de Classificação Econômica Brasil 2008. [citado 20 mar 2008]. Disponível em: http://www.abep.org/novo/ Content.aspx?ContentID $=139$.

7. Guigoz Y, Vellas B. The Mini Nutritional Assessment (MNA) for grading the nutritional state of elderly patients: presentation of the MNA, history d validation Nestrle Nutr Workshop Ser Clin Perfrom Programme. 1999; 1: 3-11.

8. Moreira TMM. Nutritional screening and assessment of an elderly group of Lar de São José of Covilhã. Porto: Universidade do Porto; 2009.

9. Benedetti TRB, Mazo GZ, Barros MVG. Aplicação do questionário internacional de atividades físicas (IPAQ) para avaliação do nível de atividades físicas de mulheres idosas: validade concorrente e reprodutibilidade testereteste. Rev Bras Cienc Mov. 2004; 12: 25-34.

10. Organização Mundial da Saúde. Classificação Internacional de Doenças e problemas relacionados à saúde. Décima revisão. São Paulo: Centro Colaborador da OMS para Classificação de Doenças em Português; 1993.

11. Lawton MP, Brody EM. Assessment of older people: selfmaintaining and instrumental activities of daily living. Gerontologist. 1969; 9: 179-86.

12. Almeida OP, Almeida AS. Confiabilidade da versão brasileira da escala de depressão em geriatria (GDS) versão reduzida. Arq Neuropsiquiatr. 1999; 57: 421-6. 
13. Pfeiffer E. A short portable mental status questionnaire for the assessment of organic brain deficit in elderly patients. J Am Geriatr Soc. 1975; 23: 433-41.

14. Barros AJD, Hirakata V. Alternatives for regression in cross-sectional studies: an empirical comparison of models that directly estimate the prevalence ratio. BMC Med Res Methodol. 2003; 3: 21.

15. Victora CG, Uttly SR, Fuchs SC, Olinto MTA. The role of conceptual frameworks in epidemiological analysis: a hierarchical approach. Int J Epidemiol. 1997; 26: 224-7.

16. Roberts KC, Wolfson C, Payette H. Predictors of nutritional risk in community-dwelling seniors. Can J Public Health. 2007; 98: 331-6.

17. Fisher SG. Community-based nutrition programs and services are needed to improve the health of older adults. J Am Diet Assoc. 2007; 107: 265-72.

18. Martins IS, Meléndez GV, Cervato AM. Estado nutricional de grupamentos sociais da área metropolitana de São Paulo, Brasil. Cad Saude Publica. 1999; 15: 71-8.

19. Coqueiro RS, Barbosa AR, Borgatto AF. Nutritional status, health conditions and socio-demographic factors in the elderly of Havana, Cuba: data from SABE Survey. $J$ Nutr Health Aging. 2010; 14: 803-8.

20. Azevedo LC, Fenilli M, Neves L, Almeida CB, Farias MB, Breitkopf'T. Principais fatores da mini-avaliação nutricional associada a alterações nutricionais de idosos hospitalizados. Arq Cat Med. 2007; 36: 7-14.

21. Monteiro CA. A dimensão da pobreza, da fome e da desnutrição no Brasil. Estud Av. 1995; 9: 195-207.

22. Rosa TEC, Benicio MHD, Latorre MRDO, Ramos LR. Fatores determinantes da capacidade funcional entre idosos. Rev Saude Publica. 2003; 37: 40-8

23. Virtuoso Júnior JS, Guerra RO. Fatores associados às limitações funcionais em idosas de baixa renda. Rev Assoc Med Bras. 2008; 54: 430-5. 